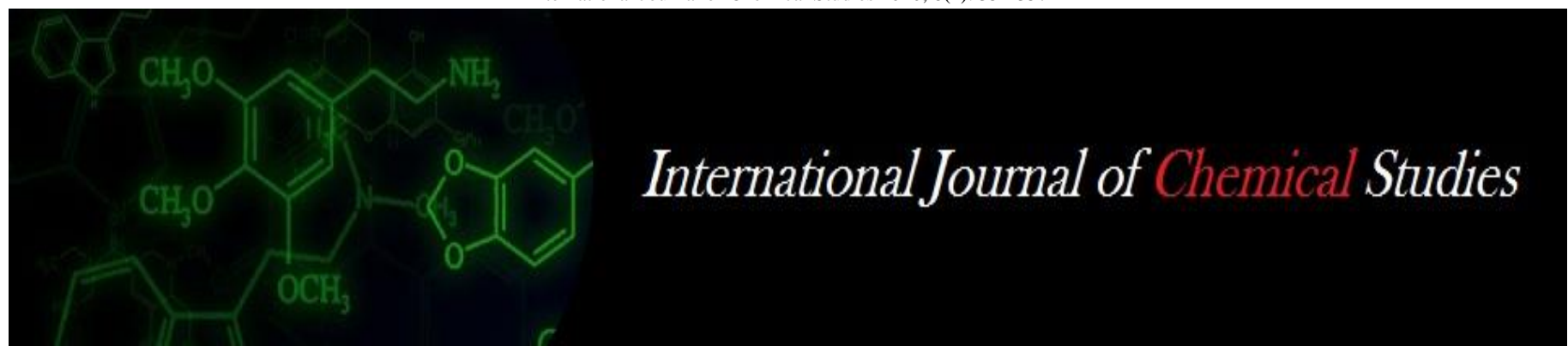

P-ISSN: 2349-8528

E-ISSN: 2321-4902

www.chemijournal.com

IJCS 2020; 8(2): 352-357

(C) 2020 IJCS

Received: 04-01-2020

Accepted: 06-02-2020

\section{NW Shinde}

Ph.D., College of Dairy Science and Food Technology, CGKV,

Raipur, Chhattisgarh, India

\section{S Kartikeyan}

College of Dairy Science and

Food Technology, CGKV,

Raipur, Chhattisgarh, India

\section{AK Agrawal}

College of Dairy Science and

Food Technology, CGKV,

Raipur, Chhattisgarh, India

\section{BK Goel}

College of Dairy Science and

Food Technology, CGKV,

Raipur, Chhattisgarh, India

\section{KK Choudhary}

College of Dairy Science and

Food Technology, CGKV,

Raipur, Chhattisgarh, India

\section{K Punita}

Krishi Vigyan Kendra,

Mahasamund, IGKV, Raipur,

Chhattisgarh, India
Corresponding Author:

NW Shinde

Ph.D., College of Dairy Science

and Food Technology, CGKV,

Raipur, Chhattisgarh, India

\section{Selection of suitable form of amaranth (Amaranthus cruentus) for development of amaranth incorporated composite fermented milk drink}

\author{
NW Shinde, S Kartikeyan, AK Agrawal, BK Goel, KK Choudhary and K Punita
}

DOI: https://doi.org/10.22271/chemi.2020.v8.i2f.8793

\begin{abstract}
The objective of this investigation was to select the suitable form of amaranth grain flour for development of composite fermented milk drink, with improved nutritional value. The product was developed using toned milk as base material with incorporation of amaranth flour (sprouted, roasted and non-roasted), sugar and FD-DVS culture CH1 (Streptococcus thermophilus and Lactobacillus delbrueckii sub sp. bulgaricus). The product evaluated for sensory acceptability using hedonic scale. The results revealed that the fermented milk drink prepared with roasted amaranth grain flour showed higher overall acceptability score (7.42) than sprouted (6.97) and non-roasted (7.22) one. Hence, roasted form of amaranth grain flour was selected for preparation composite fermented milk drink.
\end{abstract}

Keywords: Amaranth, fermented milk drink, roasting, sprouting

\section{Introduction}

Fermentation is one of the oldest and most effective methods used for conversion of raw materials into various types of value-added products by the growth of selective microorganism with distinct nutritional and sensory properties (Perotti et al., 2019) ${ }^{[19]}$. Fermentation increases the nutritive value of a product with the biosynthesis of vitamins, essential amino acids and proteins, by increasing digestibility protein, fibre, bioavailability micronutrient, and by reducing anti-nutritional factors (Rolle, 1999 cited in Modha, 2006) ${ }^{[21-13]}$

The consumption of fermented dairy products is increasing day by day throughout the world due to their beneficial effects on health (Codina et al., 2016) ${ }^{[6]}$ The world sour milk drinks market is estimated to reach USD 4,895 million by 2023 (www.mordorintelligence.com) ${ }^{[28]}$. India ranks first among the world's milk-producing nations since 1998 and milk production in the country has increased from 176.3 million tonnes in $2017-18$ to 187.7 million tonnes in 2018-19 and the per capita availability of milk in the country has increased to 394 grams per day in 2018-19 as compared to 374 grams per day in 2017-18 (www.nddb.coop) ${ }^{\text {[29] }}$. It has been projected that about $10 \%$ of total milk produced in India is used for manufacturing of traditional fermented milk products (Mistry et al., 2018) ${ }^{[12]}$.

Milk and milk products have been considered as highly nutritious food containing significant concentration macronutrients, micronutrients and bioactive molecules required for the growth and overall development of people of all ages. However, they lack fibre and essential nutrient like iron (Ahuja et al., 2017) ${ }^{[2]}$. Cereals are principal sources of energy, carbohydrates, protein, fibre and some micronutrients like iron, potassium etc. A composite milk product prepared by addition of flour of some important pseudo-cereal like amaranth, quinoa and buckwheat into milk adds value to milk and also confers health benefits to consumers (ElAidie et al., 2017 and Hussain and Garg, 2014) ${ }^{[7-10]}$.

\subsection{Fermented milk drink}

According to FSSAI, 2016 fermented milk is a milk product obtained by fermentation of milk, which may have been manufactured using other permitted raw material, by the action of suitable microorganisms and resulting in lowering of $\mathrm{pH}$ with or without coagulation (isoelectric precipitation). Fermented milk may be heat-treated after fermentation. 
The drinks based on fermented milk are composite milk products obtained by mixing fermented milk with potable water with or without the addition of whey, other milk and milk products, other permitted non-dairy ingredients and flavours and should contain a minimum of $40 \%(\mathrm{~m} / \mathrm{m})$ fermented milk. The fermented milk part should have a minimum milk protein content of $2.9 \%(\mathrm{~m} / \mathrm{m})$ and minimum titrable acidity of $0.45 \%$ (LA) (www.fssai.org.in) ${ }^{[27]}$.

\subsection{Amaranth (Amaranthus cruentus)}

Amaranth (Amaranthus cruentus) is a native species to the Andean region of South America, including Argentina, Peru, and Bolivia (www.fao.org) ${ }^{[25]}$. Amaranth is a gluten-free pseudo-cereal grain that belongs to the Amaranthaceae family. It is recognized as a promising plant genus that provides high-quality protein, unsaturated oil, and various other valuable constituents. According to the United States department of agriculture, amaranth grain contains about $13 \%$ protein, $7 \%$ fat, $65 \%$ carbohydrates and $6.7 \%$ dietary fibre (www fdc.nal.usda.gov) ${ }^{[26]}$.

The leaves and grains of the plant are often used in countries throughout Africa, the Caribbean, India, and China. In the past few years, grain amaranth (Amaranthus cruentus) has gained increased attention, due to its unique nutritional properties and versatile usage, (Narwade and Pinto, 2018) ${ }^{[17]}$. The word Amaranthus is derived from the Greek word "Anthos" (Flower) which means everlasting (Rastogi and Shukla 2013) ${ }^{[20]}$. The word amaranth, whose origins are from the Sanskrit word "Amare which means immortal, in India amaranth is known as Rajgira" in Hindi and also called Seel, Ramdana or Varti chawal in some regions. Amaranth is mostly consumed during religious fasts (Maurya and Arya, 2018) [11]. Considering the above facts; a study was undertaken to develop a composite fermented milk drink by using a suitable form of amaranth grain flour. Three different types of flour obtained from non-roasted, roasted and sprouted amaranth grain (Figure 1) were subjected to preliminary trials for selection of one to develop composite fermented milk drink. The fermented drink prepared as per methods explained in figure 2 was subjected to sensory evaluation for colour \& appearance, flavour, consistency, sweetness and overall acceptability using 9 points hedonic scale. Based on the sensory evaluation one out of the three types of flour was selected and used in the subsequent experiments

\section{Materials and Methods}

The study was carried out in the Department of Dairy Technology College of Dairy Science and Food Technology, Raipur (Chhattisgarh). The raw materials, amaranth grain
(Amaranthus cruentus), pasteurized toned milk (Brand: Amul), non-sulfated, refined cane sugar of commercial-grade (Brand: Madhur) and FD-DVS culture CH1 (Streptococcus thermophilus and Lactobacillus delbrueckii sub sp. bulgaricus) of Chr-Hansen were used in the study.

\subsection{Amaranth Grain Processing \\ 2.1.1 Sample preparation}

The procured amaranth grains sample was screened, sieved to removes all foreign materials and washed with tap water to remove dust particles (Chemeda and Bussa, 2018) ${ }^{[5]}$. The washed amaranth grains were dried in tray dryer at $55 \pm 1{ }^{\circ} \mathrm{C}$ for 4-5 h till approximate moisture content of 7 per cent was achieved (Ganguly, 2013 and Beniwal et al., 2019) ${ }^{[9-[4]}$. The grain samples were divided into three lots. One lot is used as such, the second lot was roasted and third lot was sprouted. The figure 1 depicts the preparation of flour from non-roasted, roasted and sprouted amaranth grain.

\subsubsection{Roasting of amaranth grains}

Roasting is normally done to enhance the flavour and to improve the organoleptic properties of the food grains (Murthy et al., 2008) ${ }^{[14]}$. The amaranth grains were roasted in oven (Equitron Medica Private Limited, Mumbai) at $127 \pm 1$ ${ }^{\circ} \mathrm{C}$ for 5.5 min or till golden brown colour and cooled to room temperature (Almanza et al., 2012 and Muyonga et al., 2014) [3-15].

\subsubsection{Sprouting of amaranth grains}

The raw, clean amaranth grains were soaked in distilled water 3 times the weight of grains for $24 \mathrm{~h}$ at $25 \mathrm{n}{ }^{\circ} \mathrm{C}$ (Chemeda and Bussa, 2018) ${ }^{[5]}$. The soaked water was changed after every 4 $\mathrm{h}$ interval to prevent mould growth, soaking of amaranth grain was carried out in glass jars (Omary et al., 2012) ${ }^{[18]}$. The soaked water was drained and amaranth grains were sprouted in the incubator at $26 \pm 1{ }^{\circ} \mathrm{C}$ for $48 \mathrm{~h}$ until the rootlets appeared (Najdi Hejazi and Orsat, 2017) ${ }^{[16]}$. The sprouts were rinsed after every $8 \mathrm{~h}$ interval. The sprouted amaranth grains were dried in tray dryer at $55 \pm 1{ }^{\circ} \mathrm{C}$ for $4-5 \mathrm{~h}$ till approximate moisture content of 7 per cent was achieved and rootlets were removed by scrubbing with hands (Ganguly, 2013) ${ }^{[9]}$.

\subsubsection{Flour preparation}

All the three types of processed amaranth grain (non-roasted, roasted and sprouted) were ground into flour using a mini grain flour mill and sieved through 60 mesh sieve (Sindhuja et al., 2005) ${ }^{[23]}$. The amaranth grain flour was packed in an air tight container and stored at $4^{\circ} \mathrm{C}$ for further use (Chemeda et al., 2019) ${ }^{[4]}$. 


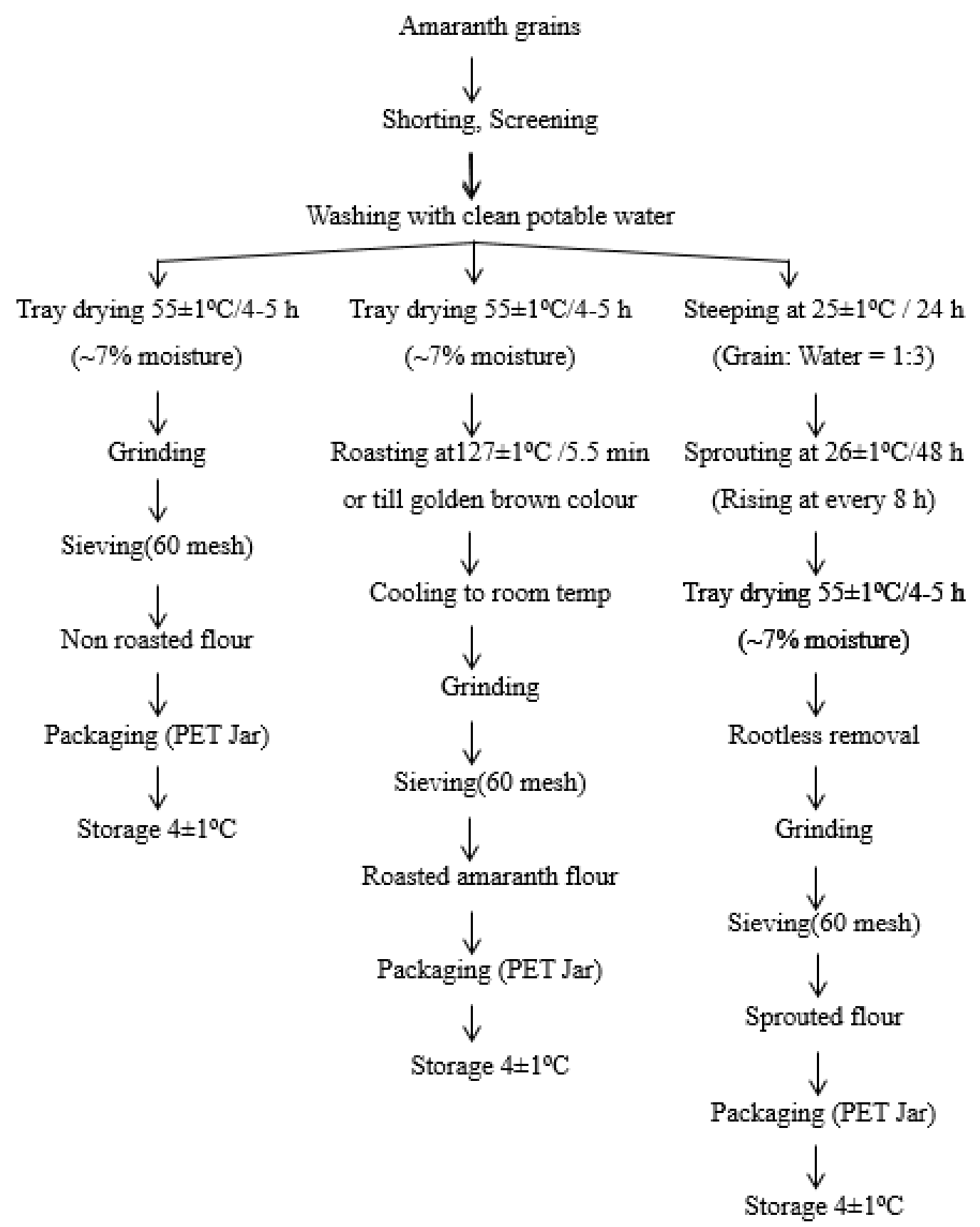

Fig 1: Flow chart for the preparation of non-roasted, roasted and sprouted amaranth grain flour

\subsection{Preparation of amaranth incorporated composite} fermented milk drink

Standard procedure for composite fermented milk drinkmaking with minor modification of the procedure adopted by Ahuja et al., (2015) [1] was used for the preparation of amaranth incorporated composite fermented milk drink (AICFMD).

Processed amaranth flour @ 5\% of the final product (w/w) was added to pasteurized toned milk (containing 3\% fat and $8.5 \%$ solids-not-fat) and mixed using electrically driven hand blender (Make: Philips). The milk and amaranth flour mix was heated to $90^{\circ} \mathrm{C} / 5$ minutes with occasional stirring and immediately cooled to $42 \pm 1^{\circ} \mathrm{C}$. The mix was inoculated with FD-DVS culture CH1 (Streptococcus thermophilus and Lactobacillus delbrueckii sub sp. bulgaricus) @ $0.009 \%$ (w/w) and was incubated at $42 \pm 1^{\circ} \mathrm{C}$ till the acidity reached to $0.9 \%$ lactic acid. Finally, the amaranth incorporated curd was broken and immediately cooled to $5 \pm 1{ }^{\circ} \mathrm{C}$ to arrest further acid production. Commercial-grade non-sulfated, refined cane sugar @ 10\% of AICFMD (w/w) was used to prepare sugar syrup $\left(50^{\circ} \mathrm{Brix}\right)$. The syrup was pasteurized by heating to 90 ${ }^{\circ} \mathrm{C}$ for $5 \mathrm{~min}$ followed by immediate cooling to $5 \pm 1{ }^{\circ} \mathrm{C}$. The pasteurized sugar syrup and the calculated amount of pasteurized chilled water were blended with curd to maintain $21.2 \%$ total solid in final AICFMD and mixed properly with electrical driven hand blender. The prepared drink was filled in $200 \mathrm{ml}$ pre-sterilised transparent polyethylene terephthalate (PET) bottles and stored under refrigeration at $5 \pm 1{ }^{\circ} \mathrm{C}$. The preparation of AICFMD is presented in figure 2. 
Pasteurized Toned milk (Fat 3\%, SNF 8.5\%)

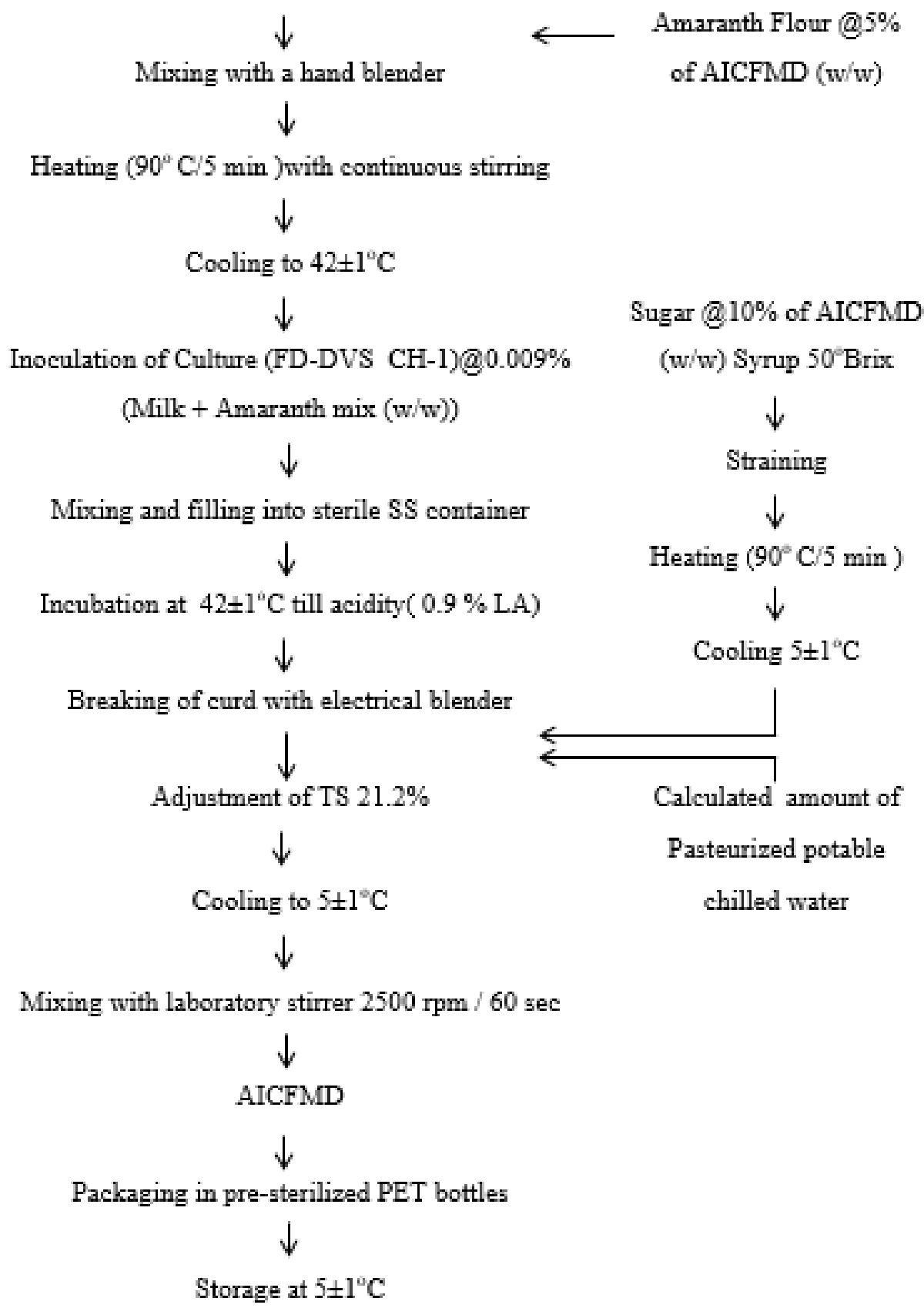

Fig 2: Flow chart for the preparation of amaranth incorporated composite fermented milk drink

\subsection{Sensory evaluation}

The composite fermented milk drink samples prepared from a different form of amaranth were drawn from the refrigerator just before sensory evaluation. The test sample was presented to the panellists in $50 \mathrm{ml}$ odourless disposable polystyrene cups with lids after assigning suitable three-digit codes. All samples were evaluated for sensory attributes viz. colour and appearance, flavour, consistency, sweetness and overall acceptability by a semi-expert panel of 5 faculty members from College of Dairy Science and Food Technology, Raipur by using a 9-point hedonic scale scorecard. Panellists were asked to rinse the mouth with lukewarm water between the samples.

\subsection{Statistical Analysis}

All the data in the present study were taken as a mean of five replicates and subjected to statistical analysis using 'Completely Randomized Design' in WASP - Web Agri Stat Package 2.0 (www.ccari.res.in) ${ }^{[30]}$.

\section{Results and Discussions}

3.1 Sensory Evaluation of amaranth incorporated composite fermented milk drinks

The sensory evaluation is a very important analytical tool in new product development. It is defined as a scientific discipline used to evoke, measure, analyze and interpret results of those characteristics of foods and materials as they are perceived by the senses of sight, smell, taste, touch and hearing. Sensory evaluation is a simple analytical tool that identifies the presence or absence of perceptible differences in terms of colour and appearance, flavour, consistency, sweetness and overall acceptability as follows.

\subsubsection{Colour and appearance}

Color and appearance attract the consumer towards a product and urge them for purchases. The data on colour and appearance score of AICFMD is presented in Table 1. The colour and appearance score ranged from 7.16 (sprouted) to 7.40 (non- roasted). The incorporation of different forms of 
amaranth flour did not affect the colour and appearance of the finished products significantly as evidenced by the non- significant difference that existed for this parameter.

Table 1: Effect of a different form of amaranth on sensory quality of fermented milk drink

\begin{tabular}{|c|c|c|c|c|}
\hline \multirow{2}{*}{ Sensory Attributes } & \multicolumn{3}{|c|}{ Form of Amaranth } & \multirow{2}{*}{ C.D at 5\% } \\
\cline { 2 - 5 } & Non-Roasted & Roasted & Sprouted & \\
\hline Colour and Appearance & $7.40 \pm 0.10$ & $7.32 \pm 0.07$ & $7.16 \pm 0.08$ & NS \\
\hline Flavour & $7.00 \pm 0.07^{\mathrm{b}}$ & $7.62 \pm 0.06^{\mathrm{a}}$ & $6.76 \pm 0.09^{\mathrm{c}}$ & 0.23 \\
\hline Consistency & $7.42 \pm 0.12^{\mathrm{a}}$ & $7.34 \pm 0.11^{\mathrm{a}}$ & $6.92 \pm 0.11^{\mathrm{b}}$ & 0.34 \\
\hline Sweetness & $7.06 \pm 0.13$ & $7.38 \pm 0.09$ & $7.04 \pm 0.07$ & $\mathrm{NS}$ \\
\hline Overall Acceptability $^{\mathrm{a}}$ & $7.22 \pm 0.06^{\mathrm{b}}$ & $7.42 \pm 0.05^{\mathrm{a}}$ & $6.97 \pm 0.07^{\mathrm{c}}$ & 0.19 \\
\hline
\end{tabular}

Values are mean of five replications. The different superscripts in a row indicate treatments differ significantly $(P<0.05)$.

\subsubsection{Flavour}

Flavor is defined as the experience of the combined perception of compounds responsible for aroma (odor) and taste (Watanabe et al., 2012) ${ }^{\text {[24] }}$. Aroma compounds are volatile and are perceived primarily with the nose, while taste refers to the proximal sense that requires direct contact of food with stimuli on the tongue to determine the quality of the ingested food (Romagny et al., 2017) ${ }^{[22]}$. The color and appearance may be the initial quality attributes that attract us to the dairy product but flavor of dairy product have the largest impact on acceptability and desire to consume it again. The slight change in flavor affects the overall quality of the product.

From Table 1 it is seen that the flavour scores of AICFMD prepared from non-roasted, roasted and sprouted amaranth grain flour ranged from 6.76 to 7.62 . The incorporation of different forms of amaranth flour significantly influenced the flavor score of AICFMD, in which the roasted form of amaranth in finished product secured the highest flavor score of 7.62 that differed significantly $(P<0.05)$ from rest of fermented milk drink samples. This might be due to the typical nutty flavour that generated in the amaranth grains when subjected to the roasting process. It is reported that roasting amaranth grains resulted in volatiles i.e. aldehydes formed by Strecker degradation including 2-methyl propanal, 3-methyl butanal, and phenyl acetaldehyde. Also, alkyl pyrazines such as methyl pyrazine, vinylpyrazine, 2, 5dimethyl ptrazine and 3-ethyl-2, 5-dimethyl pyrazine. These compounds could be characterized as corn-like, nutty, hazelnutty and having roasty odors, and they were not present in the raw seeds (Gamel and Linssen 2008) ${ }^{[8]}$.

\subsubsection{Consistency}

The data showed in Table 1 indicated that the consistency score of fermented milk drink sample prepared from sprouted amaranth grain flour $(6.92)$ was significantly $(P<0.05)$ lower than the other two samples, while the product sample prepared from non-roasted (7.42) and roasted (7.34) amaranth flour was at par with each other. The lowest consistency score of fermented milk drink sample prepared from sprouted amaranth grain flour might be a due to decrease in viscosity, water holding capacity and loss of gelling property owing to conversion (hydrolysis) of starch into simple carbohydrates during sprouting. It is reported that water binding and gel forming characteristics of starch hydrolysates are usually poor as compared to native starch molecules (Ahuja, 2015) ${ }^{[1]}$.

\subsubsection{Sweetness}

The sweetness scores of fermented milk drink sample prepared from non-roasted, roasted and sprouted amaranth grain flour were 7.06, 7.38 and 7.04 respectively and showed a non-significant difference.

\subsubsection{Overall acceptability}

The values presented in Table 1 indicated that the overall acceptability scores of fermented milk drink sample prepared from non-roasted, roasted and sprouted amaranth grain flour were $7.22,7.42$ and 6.97 respectively. It was observed that fermented milk drink sample prepared from roasted amaranth grain flour had the highest overall acceptability score of 7.42 and was found superior to the rest of the product.

\section{Conclusion}

Although color and appearance, consistency and the sweetness of AICFMD are important features, the flavor and overall acceptability of the fermented milk drinks are generally considered as the most critical and important indicator of consumer approval. In the, present study the composite fermented milk drink prepared from roasted amaranth flour has the highest flavor and overall acceptability score as compared to rest of the product. Therefore the roasted amaranth grain flour was selected for development of AICFMD.

\section{Acknowledgement}

The authors are thankful to Hon' ble VC Chhattisgarh Kamdhenu Vishwavidyalaya, Dean, College of Dairy Science and Food Technology, Raipur for providing necessary facilities to carry out this work. The first author is also thankful to Hon' ble VC, Maharashtra Animal Sciences University Nagpur and Dean, College of Dairy Technology, Warud, Pusad, MS for granting study leave to pursue Ph.D.

\section{References}

1. Ahuja KK. Development of Barley-Milk Based Fermented Probiotic Drink. Doctoral dissertation, NDRI, Karnal, 2015.

2. Ahuja KK, Singh AK, Bala K, Arora S, Sabikhi L. Optimisation of the formulation for barley-milk composite- based fermented drink. International J. Dairy Technology. 2017; 70(2):237-244.

3. Almanza IA, Perales Sanchez JX, Gutiérrez Dorado R, Mora Rochín S, Milan Carrillo J, Reyes Moreno C. Optimization of the roasting process for preparing instant amaranth (Amaranthus hypochondriacus) flours with high antioxidant activity. (Abstr.) Cereal Foods World. 2012; 57:32.

4. Beniwal SK, Devi A, Sindhu R. Effect of grain processing on nutritional and physico-chemical, functional and pasting properties of amaranth and quinoa flours. Indian Journal of Traditional Knowledge. 2019; 18(3):500-7.

5. Chemeda AS, Bussa NF. Effect of processing methods on nutritional and Anti-Nutritional value of amaranth grain; and potential future application of amaranth grain in 
injera making. International Journal of Fermented Foods. 2018; 7(1):11-20.

6. Codina GG, Franciuc SG, Mironeasa S. Rheological characteristics and microstructure of milk yogurt as influenced by quinoa flour addition. Journal of Food Quality. 2016; 39(5):559-66.

7. El-Aidie SA, El-Dieb SM, El-Nawawy M, Emara E, Sobhy H. Nutraceutical Food Based on Cereal and Probiotic Fermented Milk International Journal of Dairy Science. 2017; 12:377-84.

8. Gamel TH, Linssen JPH. Flavour compounds of popped amaranth seeds. Journal of Food Processing and Preservation. 2008; 32:656-668.

9. Ganguly S. Technology of a whey-cereal based probiotic beverage. Doctoral dissertation. NDRI, Karnal. 2013; 6870.

10. Hussain SA, Garg FC, Pal D. Effect of different preservative treatments on the shelf-life of sorghum malt based fermented milk beverage. Journal of Food Science and Technology. 2014; 51(8):1582-7.

11. Maurya NK, Arya P. Amaranthus grain nutritional benefits: A review. Journal of Pharmacognosy and Phytochemistry. 2018; 7(2):2258-62.

12. Mistry EM, Patel SM, Pinto S, Modha HM. Utilization of Moringa Pod Powder as a Value Added Ingredient in Lassi. Journal of Dairy Science and Technology. 2018; 7(1):6.

13. Modha HM. Development of a rabadi- like fermented beverage from pearl millet and milk solids. M.Tech Thesis, NDRI, Karnal, 2006.

14. Murthy KV, Ravi R, Bhat KK, Raghavarao KS. Studies on roasting of wheat using fluidized bed roaster. Journal of Food Engineering. 2008; 89(3):336-42.

15. Muyonga JH, Andabati B, Ssepuuya G. Effect of heat processing on selected grain amaranth physicochemical properties. Food Science and Nutrition. 2014; 2(1):9-16.

16. Najdi Hejazi S, Orsat V. Optimization of the malting process for nutritional improvement of finger millet and amaranth flours in the infant weaning food industry. International journal of food sciences and nutrition. 2017; 68(4):429-41.

17. Narwade S, Pinto S. Amaranth - A Functional Food. Concepts of Dairy \& Veterinary Sciences, 2018, 1(3).

18. Omary MB, Fong C, Rothschild J, Finney P. Effects of germination on the nutritional profile of gluten- free cereals and pseudocereals: A review. Cereal Chemistry. 2012; 89(1):1-4.

19. Perotti MC, Bergamini CV, Vénica CI, Vélez MA, Wolf IV, Hynes E. Production of Functional Milk-Based Beverages. In Milk-Based Beverages, Woodhead Publishing, 2019, 173-238.

20. Rastogi A, Shukla S. Amaranth: a new millennium crop of nutraceutical values. Critical reviews. Food Science and Nutrition. 2013; 53(2):109-125.

21. Rolle, R. 1999. Small scale fermentation. Proceedings of symposium on SmallScale Food Fermentations in Developing Countries, Chicago, USA.

22. Romagny S, Ginon E, Salles C. Impact of reducing fat, salt and sugar in commercial foods on consumer acceptability and willingness to pay in real tasting conditions: A home experiment. Food Quality and Preference. 2017; 56:164-172.
23. Sindhuja A, Sudha ML, Rahim A. Effect of incorporation of amaranth flour on the quality of cookies. European Food Research and Technology. 2005; 221(5):597.

24. Watanabe M, Qi X, Aida T, Smith Jr RL. The Development and Application of Microwave Heating. Book edited by Wenbin Cao, 2012.

25. www.fao.org. 24 January 2020

26. www.fdc.nal.usda.gov.28 January 2020

27. www.fssai.gov.in/notifications.php. 27 January 2020

28. www.mordorintelligence.com/industry-reports/sour-milkdrinks-market.26 January, 2020

29. www.nddb.coop/information/stats/milkprodindia. January, 2020

30. www.ccari.res.in/wasp2.0. 02 January, 2020 